\title{
Lactoferrin for the treatment of COVID-19 (Review)
}

\author{
YIDAN WANG ${ }^{1 *}$, PUXIU WANG ${ }^{1 *}$, HAORAN WANG ${ }^{2}$, YIFAN LUO ${ }^{1}$, \\ LONG WAN $^{1}$, MINGYAN JIANG ${ }^{1}$ and YANG CHU ${ }^{1}$ \\ ${ }^{1}$ Department of Pharmacy, The First Affiliated Hospital of China Medical University, Shenyang, \\ Liaoning $110000 ;{ }^{2}$ Neoland Bioscience, Weihai, Shandong 264200, P.R. China
}

Received June 15, 2020; Accepted September 25, 2020

DOI: $10.3892 /$ etm.2020.9402

\begin{abstract}
The coronavirus disease 2019 (COVID-19) outbreak was caused by infection with the severe acute respiratory syndrome coronavirus 2 (SARS-CoV-2). The clinical outcomes of elderly individuals and those with underlying diseases affected by COVID-19 are serious, and may result in acute respiratory distress syndrome (ARDS) and even mortality. Currently, the clinical treatments for COVID-19 mostly involve symptom alleviation measures and non-specific broad spectrum antiviral drugs, as highly effective antiviral drugs and vaccines are not yet available. Lactoferrin (LF) is a safe iron-binding glycoprotein that is present in the milk of the majority of mammals and exhibits broad-spectrum antiviral activity, including against coronaviruses. In addition, LF also exhibits anti-inflammatory, anti-infective and immune-regulating properties, which are in line with the treatment requirements for SARS-CoV-2 infection. Therefore, the use of LF may be of value in the prevention and/or management of COVID-19. The aim of the present review was to summarize the previous reports on the antiviral properties of LF and compare these with the characteristics of SARS-CoV-2 infection, in order to determine whether LF could be used to assist in the prevention of COVID-19 and to investigate the possible underlying mechanisms governing its mode of action.
\end{abstract}

\footnotetext{
Correspondence to: Professor Mingyan Jiang or Professor Yang Chu, Department of Pharmacy, The First Affiliated Hospital of China Medical University, 155 Nanjing North Street, Shenyang, Liaoning 110000, P.R. China

E-mail: jiangmingyan0414@163.com

E-mail: 15002422786@163.com

${ }^{*}$ Contributed equally
}

Key words: lactoferrin, severe acute respiratory syndrome coronavirus 2, coronavirus disease 2019, receptors of host cells, immunomodulatory effects

\section{Contents}

1. Introduction

2. Two-stage interaction with receptors on host cells

3. Immunomodulatory effects of LF

4. Fusion between LF and the viral envelope

5. Discussion and conclusion

\section{Introduction}

Severe acute respiratory syndrome coronavirus 2 (SARS-CoV-2) is a novel $\beta$-coronavirus, which has caused an ongoing outbreak of atypical pneumonia worldwide. According to official data from the World Health Organization (1), by October 7, 2020, >35,347,404 people have been affected by the SARS-CoV-2, and $>1,039,406$ patients had succumbed to the disease. A number of countries have required that residents reduce social activities and self-quarantine to limit the spread of coronavirus disease 2019 (COVID-19), which has caused major changes and disruptions to daily life, including work, school, sports, events and social activities $(2,3)$. During the mandatory isolation, it is crucial to maintain mental and physical health through physical exercise $(4,5)$. The clinical manifestations of COVID-19 are non-specific and range from asymptomatic infection to severe respiratory failure. The most common symptoms of COVID-19 include cough, fever and dyspnea (6). Elderly individuals and those with underlying conditions, such as cardiovascular and lung diseases, may suffer from more severe symptoms and mortality (7). Obesity has also been identified as a risk factor for the disease (8). Environmental factors, social customs and epidemic-specific attitudes, administrative issues and other factors will all have a major impact on the prevalence of COVID-19 (9).

The pathogen of COVID-19, SARS-CoV-2, is a positive-sense single-stranded RNA virus of the $\beta$-coronavirus genus $(10,11)$. SARS-CoV-2 has been demonstrated to have a spherical morphology with spike projections on the surface (12), and it shares a high sequence identity with severe acute respiratory syndrome coronavirus (SARS-CoV) (13). The spike $\mathrm{S}$ glycoprotein serves a major role in viral infections and is one of the main targets in the design of therapeutic drugs and vaccines (14). At present there is no specific therapeutic drug or vaccine for SARS-CoV-2 (15), so the drugs currently used are aimed at suppressing inflammation or improving 
symptoms. Some antiviral drugs appear to serve a positive role in treating COVID-19, particularly at the early phase, such as interferon, lopinavir, chloroquine/hydroxychloroquine and ribavirin (16). Traditional Chinese medicines, including Lianhuaqingwen, have also demonstrated beneficial outcomes when used to treat cases with mild symptoms (17). However, further clinical trials of drugs and vaccines for SARS-CoV-2 are required to assess their efficacy and safety. Fig. 1 presents the SARS-CoV-2 infection. SARS-CoV-2 can enter the host cell through the angiotensin-converting enzyme 2 (ACE2) site. Infected individuals usually exhibit non-specific symptoms such as a cough and fever. Clinically, antiviral drugs are usually used for treatment, but there are no specific drugs and vaccines that are used.

Lactoferrin (LF), which is an iron-binding glycoprotein with a molecular weight in the range of 70-80 kDa, can transport iron in the blood and serum (18). LF is a simple polypeptide chain that is assembled into two symmetrical lobes (19). Each lobe contains two domains, which can bind a metal atom. It has been previously reported that the antiviral effect of LF is mediated by binding iron and is not affected by unsaturated iron levels (20). According to the available literature, the sequences and structures of LF from different sources (including from human, bovine and camel) are similar, except the N-terminal part of camel LF, as the first 50 residues of the N-terminus of camel LF shares less than $40 \%$ sequence identityl with other sources of lactoferrin $(21,22)$. LF is produced by mucosal epithelial cells in a number of different mammalian and fish species, and is found in mucosal secretions, bodily fluids and secondary neutrophil granules (23).

After LF is successfully isolated and purified, a number of its physiological activities have been gradually uncovered, including antifungal, antiviral and anti-inflammatory activities, as well as effects on the immune response $(18,24,25)$. These activities are mediated through the capacity of LF to bind iron and to interact with components of the host and the pathogens (23). LF is positively charged in vivo, and can bind large molecules with negative charges, such as lipopolysaccharides and glycosaminoglycans, which is one of the key mechanisms underlying its antiviral activity (26). The protective effects of LF were first confirmed in 1987 in mice infected with the polycythemia-inducing strain of friend virus complex (27). LF has been identified to be effective against several viruses, which are listed in Table I (28-37).

COVID-19 is often characterized by an unusually long asymptomatic stage (3-14 days), while asymptomatic patients may be equally, if not more, contagious compared with symptomatic patients, which makes prevention extremely difficult, particularly during the flu season (38). The mechanism behind the asymptomatic stage may involve the fact that SARS-CoV-2 has developed an additional furin protease cleavage site in the spike protein (between the S1 and S2 domains), which enables the virus to infect and proliferate in large quantities in the nostril, salivary glands and throat, where furin protease and ACE2 are both expressed at high levels (39). Over a period of time, the virus proliferating in the upper respiratory tract can migrate to the lower respiratory tract and infect others via fluid droplets. If prophylactic measures are taken in time to reduce the virus load and/or prevent infection of other cells, the interpersonal infectivity and severity of later symptoms may be markedly reduced.
From the perspective of the SARS-CoV-2 infection process, preventing viral particles from entering the cells and interfering with endocytic pathways, preventing post-translational processing of multiple proteins, and targeting cell signaling pathways, are some of the approaches that can be used to identify effective therapies (11). In addition, due to the similarities between SARS-CoV-2 and SARS-CoV, drugs that have a therapeutic effect against SARS-CoV may also be considered as a possible treatment plan. The antiviral effect of LF is mediated through preventing the virus from binding to the target cell surface, which would be particularly effective during the early amplification phase of the virus in the salivary glands, throat and upper respiratory tract (40). LF has strong and extensive antivirus properties and therefore, it can be hypothesized the LF may be used as a potential drug for the treatment of COVID-19.

\section{Two-stage interaction with receptors on host cells}

To achieve infection, the virus must first attach to the host cell and then penetrate the cell membrane. There is a highly alkaline region near the $\mathrm{N}$-terminal of LF, which may be combined with a variety of negatively charged macromolecules (41). This is an important basis for the antiviral activity of LF, as a variety of negatively charged macromolecules, such as glycosaminoglycans, often act as receptors on the surface of host cells that combine with viruses $(42,43)$. It has been demonstrated that heparan sulfate proteoglycans (HSPGs) serve important roles in inhibiting human respiratory syncytial virus, Venezuelan equine encephalitis virus (44), Echovirus (45), herpes simplex virus (HSV), dengue virus (43) as well as other viruses (46).

Novel coronavirus is the pathogen of SARS. Its high infectivity, high mortality and low cure rates make it a major threat to public health (47). SARS-CoV is an enveloped, positive-strand RNA virus, composed of spike, envelope, membrane and nucleocapsid protein (48). SARS-CoV attaches to host cells by binding HSPGs (49), which are also the binding sites for LF on host cells (50). It has been demonstrated that LF can protect the host against a variety of viral infections by preventing the internalization of viruses, such as HSV, and by occupying their binding sites (51). The protective effects of LF against SARS-CoV Pseudovirus infection of 293E/ACE2-Myc cells has been investigated (31). It has also been demonstrated that HSPGs (binding sites facilitating SARS-CoV entry) are distributed on the host cell surface and LF occupies these binding sites to prevent the internalization of SARS-CoV and infection of host cells in the early stages. Therefore, LF may be useful as a potential therapeutic drug candidate for protecting host cells against SARS-CoV infections.

SARS-CoV-2 shares $\sim 80 \%$ identity of the genome, similar receptor-binding domain (RBD) structures and cellular receptors (such as ACE2) with SARS-CoV (Fig. 2), and the $\alpha 1$ helix of the RBD binds to the peptidase domain (PD) of ACE2 via polar action (52). ACE2 has been demonstrated to be the primary receptor, while dendritic cell-specific intercellular adhesion molecule 3-grabbing non-integrin (DC-SIGN) is another controversial independent receptor of SARS-CoV-2 $(53,54)$. DC-SIGN may be a factor that promotes ACE2-mediated infection (55). Although, to the best of our knowledge, there are no studies demonstrating that LF can 


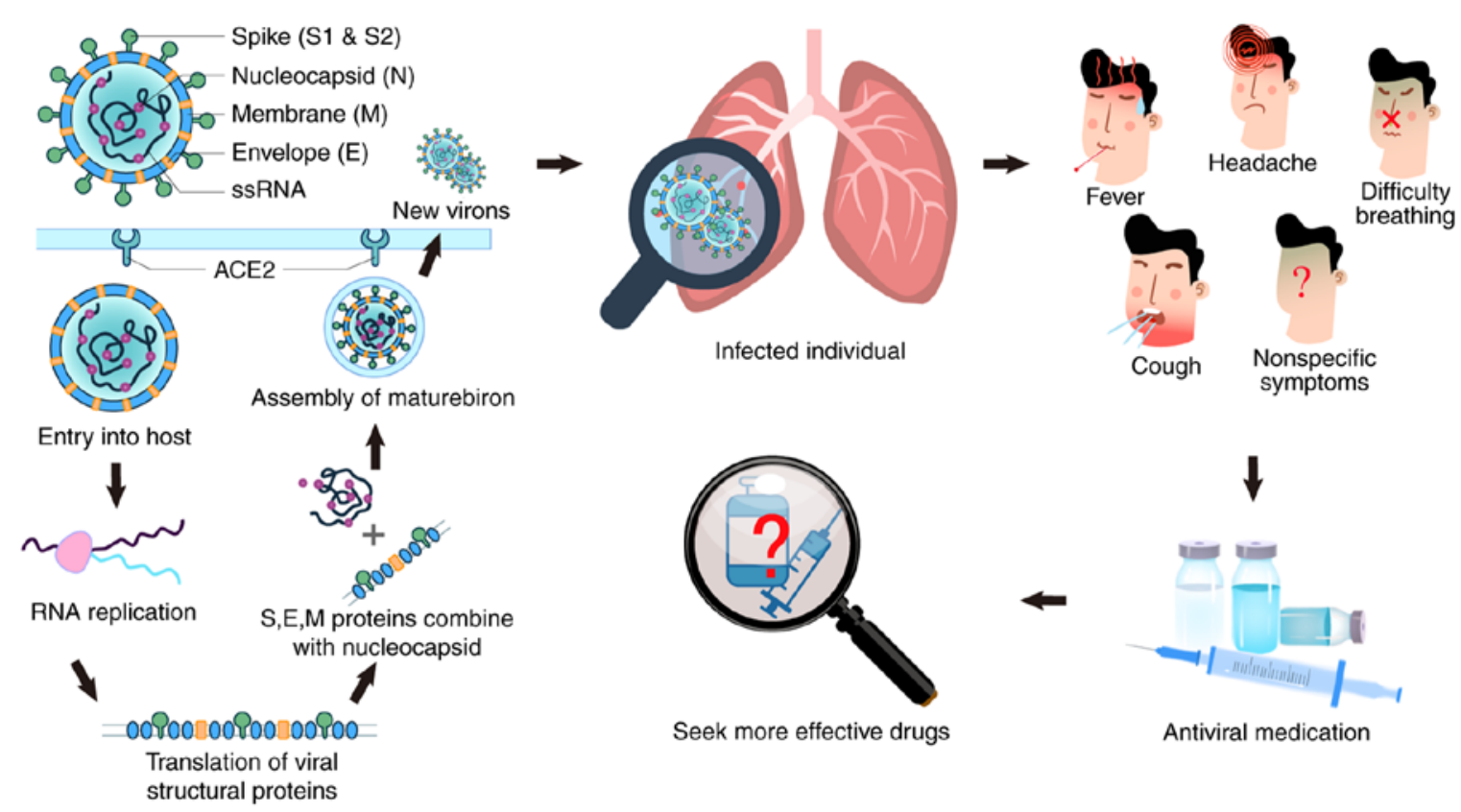

Figure 1. The SARS-CoV-2 infection. SARS-CoV-2 is composed of Spike, Nucleocapsid, Membrane, Envelope, and ssRNA. It binds to the ACE2 receptor on the surface of the host cell and enters the host cell. After a series of processes such as RNA replication and translation, it increases in value to obtain new virus. Infected individuals usually present with symptoms including a fever and headache. ssRNA, single-stranded RNA; ACE2, angiotensin-converting enzyme 2 .

protect host cells by binding to ACE2, it has been demonstrated that LF can protect the host cell against dengue virus infection via binding to sites on the cell membrane, including DC-SIGN, heparan sulfate (HS) and low-density lipoprotein receptors (32). Therefore, it may be hypothesized that LF can also inhibit ACE2-mediated infection by binding to DC-SIGN. Fig. 2 presents the interactions between SARS-CoV-2-RBD and ACE2 (52).

In addition, it has been demonstrated that ACE2 is also abundantly expressed in gastrointestinal epithelial cells $(56,57)$. Therefore, host cell internalization of SARS-CoV-2 may be identified in the gastrointestinal tract, and can lead to active infection and replication (13). Following oral administration, abundant LF remains on the lining of the gastrointestinal tract and protects host cells against infection by SARS-CoV-2 (18).

\section{Immunomodulatory effects of LF}

In addition to its interaction with host cells, LF can also enhance antiviral protection by modulating the immune response, such as enhancing phagocytosis and inducing apoptosis, among other functions (58). The immunomodulatory effects of LF have attracted attention as LF defends against infection and excessive inflammation, which is achieved through interaction with immune cells and cytokines (59). The immunomodulatory effects include i) enhancing the antigen expression ability of $\mathrm{B}$ cells and ii) regulating the function of T cells (60).

LF receptors (LFRs) are located on the surface of a variety of immune cells, such as various lymphocytes, macrophages and dendritic cells $(61,62)$. LF can reduce the release of inflammatory factors by promoting the differentiation of $\mathrm{CD}^{+} \mathrm{T}$ cells into Th1 cells (63). In addition, LF can stimulate neutrophil aggregation at the site of inflammation, activate phagocytosis by polymorphonuclear leukocytes and macrophagocytes, and increase the activity of natural killer (NK) cells. Oral administration of LF can enhance the killing activity of NK cells against tumor and virus-infected cells by facilitating the production of interleukin (IL)-18 (64). Furthermore, LF can increase the level of IL-12 in macrophagocytes, which triggers the migration of macrophages to inflammatory sites and activates $\mathrm{CD}^{+} \mathrm{T}$ cells (59). On the other hand, cytokines are important for the immunomodulatory effects of LF. LF induces the expression of type I interferons (IFN- $\alpha / \beta)$ and inhibits virus replication (58). IFN- $\alpha / \beta$ are known as potent antiviral cytokines and immunomodulators, which lead to the production of numerous antiviral bioactive compounds and cytokines (65). In summary, LF may be used as a natural immunomodulator for the treatment of COVID-19 (66).

\section{Fusion between LF and the viral envelope}

The virus infects host cells through fusion of its envelope with the host cell membrane, which is a key step during viral infection. It has been demonstrated that LF binds to the substances mediating the infection process on the virus envelope and inhibits fusion, thus preventing infection (67). The binding sites differ among different viruses. Hemagglutinin (HA) is the binding site on the H1N1 virus, and LF has been demonstrated to inhibit infection via fusion with HA (28). HA, which is a glycoprotein expressed in the virus envelope, is a key factor in the process of viral infection. Following LF binding to HA, the interaction and fusion between the glycoprotein on the virus surface and receptors on the host cell are inhibited, thereby preventing infection. In addition, LF inhibits respiratory syncytial virus (RSV), which is associated with a serious respiratory disease such as otitis media and lower respiratory tract involvement (LRTI) in infants (68), through fusion with the F protein on the virus envelope (27). LF binds to the F1 
Table I. The antivirus activities of LF for some viruses.

\begin{tabular}{|c|c|c|c|c|c|c|}
\hline Authors, year & Type of virus & Enveloped/naked & DNA/RNA & Sources of LF & Mechanism & (Refs.) \\
\hline Oda et al, 2020 & Influenza A & Enveloped & RNA & Bovine & $\begin{array}{l}\text { Interfering with the } \\
\text { fusogenic function of } \\
\text { viral hemagglutinin }\end{array}$ & (28) \\
\hline Sano et al, 2003 & RSV & Enveloped & RNA & Human & $\begin{array}{l}\text { Modulating RSV-induced } \\
\text { IL- } 8 \text { secretion and binding } \\
\text { to RSV F protein }\end{array}$ & (29) \\
\hline Pietrantoni et al, 2003 & Adenovirus & Naked & DNA & Bovine & $\begin{array}{l}\text { Binding to the adenovirus } \\
\text { penton base and competing } \\
\text { with viral particles for cell } \\
\text { membrane HS inserted in } \\
\text { target cell membranes }\end{array}$ & $(30)$ \\
\hline Lang et al, 2011 & SARS-CoV & Enveloped & RNA & Bovine & $\begin{array}{l}\text { Enhancing Natural killer } \\
\text { cell activity and stimulating } \\
\text { neutrophil aggregation and } \\
\text { adhesion, binding to the } \\
\text { heparan sulfate } \\
\text { glycosaminoglycan (HSPG) } \\
\text { and blocking the preliminary } \\
\text { interaction between } \\
\text { SARS-CoV and host cells }\end{array}$ & (31) \\
\hline Chen et al, 2017 & Dengue Virus & Enveloped & RNA & Bovine & $\begin{array}{l}\text { Interacting with Heparan } \\
\text { Sulfate, Low-Density } \\
\text { Lipoprotein Receptor and } \\
\text { DC-SIGN }\end{array}$ & (32) \\
\hline Weng et al, 2005 & Enterovirus 71 & Naked & RNA & Bovine & $\begin{array}{l}\text { Binding to viral protein } 1 \\
\text { protein and host cells }\end{array}$ & (33) \\
\hline Pietrantoni et al, 2015 & Toscana Virus & Enveloped & RNA & Bovine & $\begin{array}{l}\text { Binding to Heparan } \\
\text { Sulphate }\end{array}$ & (34) \\
\hline Beljaars et al, 2004 & CMV & Enveloped & DNA & Human & $\begin{array}{l}\text { Inhibition of CMV cell } \\
\text { entry and indirect activities } \\
\text { of lactoferrin on CMV } \\
\text { infections via stimulation } \\
\text { of the immune system }\end{array}$ & (35) \\
\hline $\begin{array}{l}\text { Ammendolia } \\
\text { et al, } 2007\end{array}$ & $\begin{array}{l}\text { Herpes Simplex } \\
\text { Virus type } 1 \\
(\mathrm{HSV}-1)\end{array}$ & Enveloped & DNA & Bovine & $\begin{array}{l}\text { Competing with HSV-1 } \\
\text { for heparan sulphate } \\
\text { receptor on cell surface } \\
\text { and affecting a post-entry } \\
\text { step of viral infection by } \\
\text { preventing VP-16 from being } \\
\text { translocated to the nucleus }\end{array}$ & $(36)$ \\
\hline Ishikawa et al, 2013 & MNV & Naked & RNA & Bovine & $\begin{array}{l}\text { Inducing the expression of } \\
\text { anti-viral cytokine mRNA, } \\
\text { such as IFN-a and IFN-b, } \\
\text { which are involved in the } \\
\text { inhibition of MNV replication } \\
\text { in the early phase of infection }\end{array}$ & (37) \\
\hline
\end{tabular}

RSV, Respiratory syncytial virus; IL, interleukin; HS, heparan sulfate; SARS-CoV, severe acute respiratory syndrome coronavirus; HSPG, heparan sulfate proteoglycans; DC-SIGN, dendritic cell-specific intercellular adhesion molecule 3-grabbing non-integrin; CMV, cytomegalovirus; MNV, mouse norovirus; IFN, interferon. 


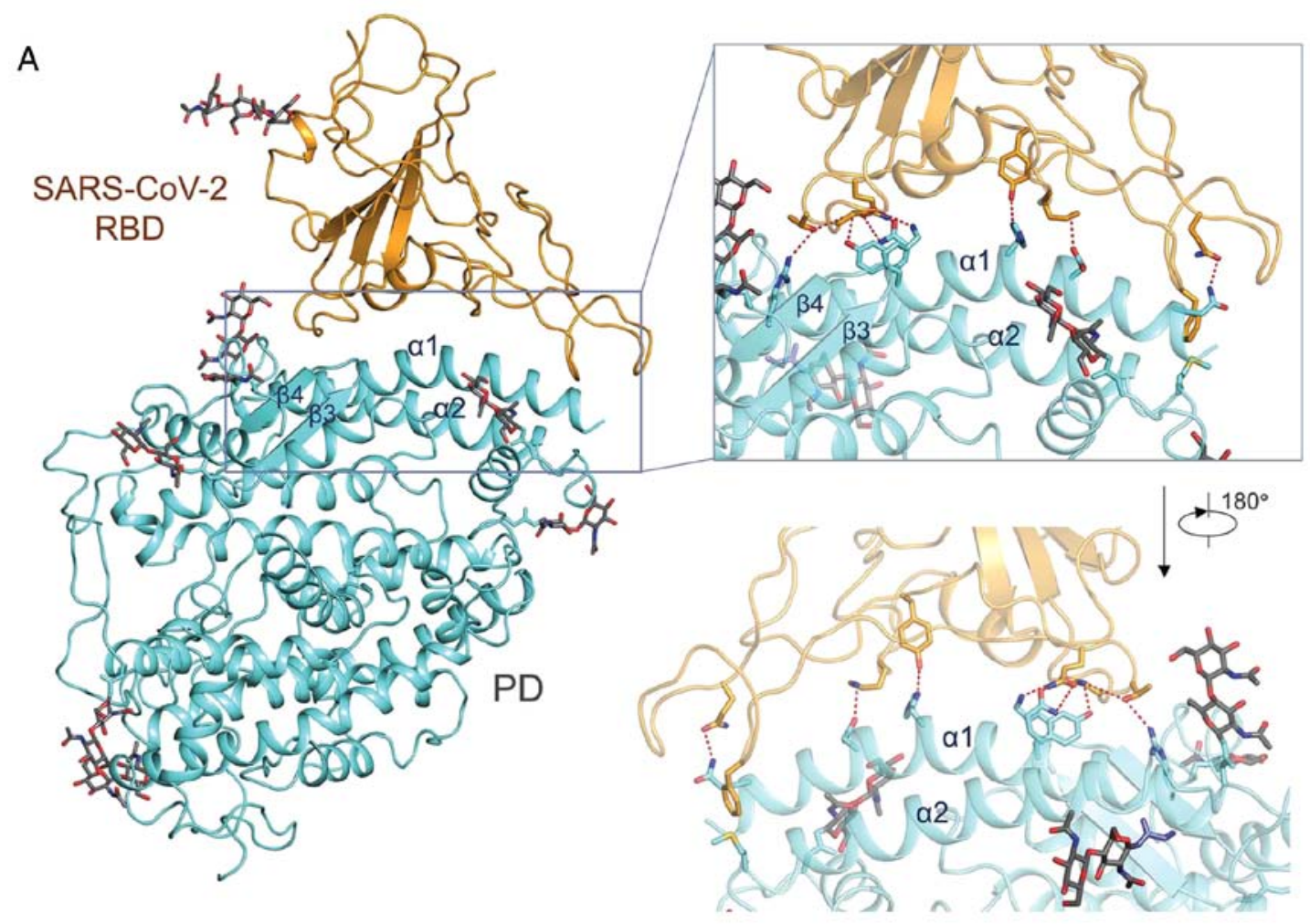

B

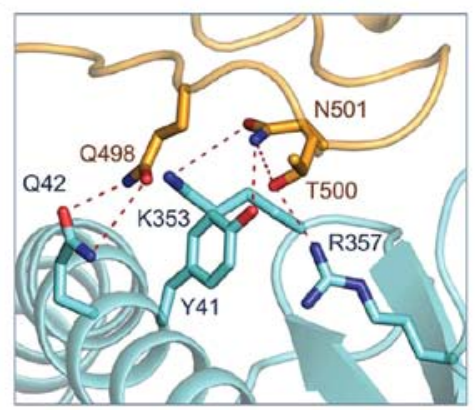

C

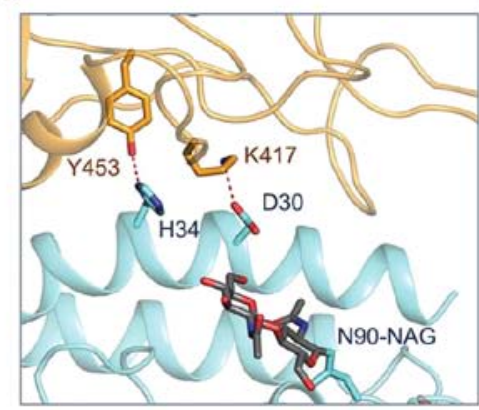

D

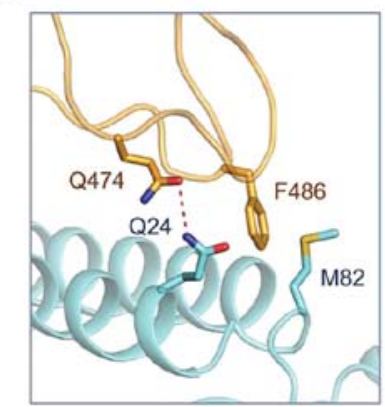

Figure 2. Interactions between SARS-CoV-2-RBD and ACE2. Yellow, the RBD of SARS-CoV-2; blue, the PD of ACE2. The red dotted line indicates the polar interaction. (A) The interaction between RBD and ACE2 is mainly through $\alpha 1$ helix, $\alpha 2$ helix, $\beta 3$ and $\beta 4$. (B-D) The specific details of the interface. Reproduced with permission (52). NAG, N-acetylglucosamine; SARS-CoV-2, severe acute respiratory syndrome coronavirus 2; RBD, receptor-binding domain; ACE2, angiotensin-converting enzyme 2.

subunit of the F protein, thereby inhibiting the entry of RSV into epithelial cells, preventing the inflammatory response caused by RSV, and decreasing the infection of Hep-2 cells. LF protects the host cell against infection by adenovirus by specifically binding to its penton base (23). Overall, the protective activity of LF against viral infections is notable. However, whether LF is also effective in SARS-CoV-2 must be further investigated, and it is necessary to identify the binding sites on SARS-CoV-2.

\section{Discussion and conclusion}

The rapid spread of the SARS-CoV-2 pandemic has become a major global health concern. It is therefore urgent to develop effective therapeutic agents to prevent and treat SARS-CoV-2 infection. LF has exhibited extensive, broad-spectrum antiviral activity, indicating its potential for the treatment and prevention of SARS-CoV-2 $(21,40)$. For example, LF treatment on HSPGs and ACE2 can prevent SARS-CoV from infecting host cells (31), and LF has extensive immunoregulatory and anti-inflammatory effects $(69,70)$, which may prove useful in the treatment of SARS-CoV-2 and the prevention of its devastating effects on multiple target organs. Furthermore, compared with other antiviral drugs, LF has a better safety profile. The use of LF may therefore hold promise in the treatment of COVID-19 and warrants further investigation.

However, there were certain limitations to the current review. The aforementioned possible effects of LF on SARS-CoV-2 are based on the effects of LF on other viruses, and there is currently a lack of direct research on the effects of LF on SARS-CoV-2. In addition, there remains certain problems in applying LF in the clinical setting. For example, it remains unknown which state of LF is more effective in treating SARS-CoV-2, namely unsaturated vs. saturated, human-derived vs. bovine-derived, whereas the combined metal, specific dosage and route of administration have yet 
to be clearly determined, and these issues must be considered and resolved before applying LF in the clinical setting for the treatment of COVID-19.

In conclusion, the use of LF appears to be a promising approach to the treatment of COVID-19, but further investigations are required to verify its antiviral activity in vitro and in vivo.

\section{Acknowledgements}

Not applicable.

\section{Funding}

Liaoning Province Natural Science Foundation of China (grant no. 2020-BS-106).

\section{Availability of data and materials}

Not applicable.

\section{Authors' contributions}

YC, HW and MJ conceptualized the study. YW, PW, HW, YL, LW performed validation, research and reviewed the data. YW and PW wrote the manuscript. YW, PW, YC and MJ reviewed the manuscript. All authors read and approved the final manuscript.

\section{Ethics approval and consent to participate}

Not applicable.

\section{Patient consent for publication}

Not applicable.

\section{Competing interests}

The authors declare that they have no competing interests.

\section{References}

1. World Health Organization (WHO): WHO Coronavirus Disease (COVID-19) Dashboard. WHO, Geneva, 2020. https://covid19. who.int/. Accessed October 7, 2020.

2. Giustino V, Parroco AM, Gennaro A, Musumeci G, Palma A and Battaglia G: Physical activity levels and related energy expenditure during COVID-19 quarantine among the Sicilian active population: A Cross-Sectional Online Survey Study. Sustainability 12: 4356, 2020.

3. Paoli A and Musumeci G: Elite Athletes and COVID-19 lockdown: Future health concerns for an entire sector. J Funct Morphol Kinesiol 5: 30, 2020.

4. Maugeri G, Castrogiovanni P, Battaglia G, Pippi R, D'Agata V, Palma A, Di Rosa M and Musumeci G: The impact of physical activity on psychological health during Covid-19 pandemic in Italy. Heliyon 6: e04315, 2020.

5. Ravalli S and Musumeci G: Coronavirus Outbreak in Italy: Physiological benefits of home-based exercise during pandemic. J Funct Morphol Kinesiol 5: 31, 2020

6. Zhai P, Ding Y, Wu X, Long J, Zhong Y and Li Y: The epidemiology, diagnosis and treatment of COVID-19. Int J Antimicrob Agents 55: 105955, 2020.

7. Chen N, Zhou M, Dong X, Qu J, Gong F, Han Y, Qiu Y, Wang J, Liu Y, Wei Y, et al: Epidemiological and clinical characteristics of 99 cases of 2019 novel coronavirus pneumonia in Wuhan, China: A descriptive study. Lancet 395: 507-513, 2020.
8. Petrakis D, Margină D, Tsarouhas K, Tekos F, Stan M,Nikitovic D, Kouretas D, Spandidos DA and Tsatsakis A: Obesity-a risk factor for increased COVID-19 prevalence, severity and lethality. Mol Med Rep 22: 9-19, 2020.

9. Goumenou M, Sarigiannis D, Tsatsakis A, Anesti O, Docea AO, Petrakis D, Tsoukalas D, Kostoff R, Rakitskii V, Spandidos DA, et al: COVID-19 in Northern Italy: An integrative overview of factors possibly influencing the sharp increase of the outbreak (Review). Mol Med Rep 22: 20-32, 2020.

10. Lai CC, Shih TP, Ko WC, Tang HJ and Hsueh PR: Severe acute respiratory syndrome coronavirus 2 (SARS-CoV-2) and coronavirus disease-2019 (COVID-19): The epidemic and the challenges. Int J Antimicrob Agents 55: 105924, 2020.

11. Nitulescu GM, Paunescu H, Moschos SA, Petrakis D, Nitulescu G, Ion GND, Spandidos DA, Nikolouzakis TK, Drakoulis $\mathrm{N}$ and Tsatsakis A: Comprehensive analysis of drugs to treat SARS-CoV-2 infection: Mechanistic insights into current COVID-19 therapies (Review). Int J Mol Med 46: 467-488, 2020.

12. Li H, Zhou Y, Zhang M, Wang H, Zhao Q and Liu J: Updated approaches against SARS-CoV-2. Antimicrob Agents Chemother 64: e00483-20, 2020.

13. Yeo C, Kaushal S and Yeo D: Enteric involvement of coronaviruses: Is faecal-oral transmission of SARS-CoV-2 possible? Lancet Gastroenterol Hepatol 5: 335-337, 2020.

14. Dehelean CA, Lazureanu V, Coricovac D, Mioc M, Oancea R, Marcovici I, Pinzaru I, Soica C, Tsatsakis AM and Cretu O: SARS-CoV-2: Repurposed drugs and novel therapeutic approaches-insights into chemical structure-biological activity and toxicological screening. J Clin Med 9: 2084, 2020.

15. Calina D, Docea AO, Petrakis D, Egorov AM, Ishmukhametov AA, Gabibov AG, Shtilman MI, Kostoff R, Carvalho F, Vinceti M, et al: Towards effective COVID-19 vaccines: Updates, perspectives and challenges (Review). Int J Mol Med 46: 3-16, 2020.

16. Ren J, Zhang AH and Wang XJ: Traditional Chinese medicine for COVID-19 treatment. Pharmacol Res 155: 104743, 2020.

17. Runfeng L, Yunlong H, Jicheng H, Weiqi P, Qinhai M, Yongxia S, Chufang L, Jin Z, Zhenhua J, Haiming J, et al: Lianhuaqingwen exerts anti-viral and anti-inflammatory activity against novel coronavirus (SARS-CoV-2). Pharmacol Res 156: 104761, 2020.

18. Wang B, Timilsena YP, Blanch E and Adhikari B: Lactoferrin: Structure, function, denaturation and digestion. Crit Rev Food Sci Nutr 59: 580-596, 2019.

19. Baveye S, Elass E, Mazurier J, Spik G and Legrand D: Lactoferrin: A multifunctional glycoprotein involved in the modulation of the inflammatory process. Clin Chem Lab Med 37: 281-286, 1999.

20. Lönnerdal B and Iyer S: Lactoferrin: Molecular structure and biological function. Annu Rev Nutr 15: 93-110, 1995.

21. Redwan EM, Uversky VN, El-Fakharany EM and Al-Mehdar H: Potential lactoferrin activity against pathogenic viruses. C R Biol 337: 581-595, 2014.

22. Khan JA, Kumar P, Paramasivam M, Yadav RS, Sahani MS, Sharma S, Srinivasan A and Singh TP: Camel lactoferrin, a transferrin-cum-lactoferrin: Crystal structure of camel apolactoferrin at $2.6 \mathrm{~A}$ resolution and structural basis of its dual role. J Mol Biol 309: 751-761, 2001.

23. González-Chávez SA, Arévalo-Gallegos S and Rascón-Cruz Q: Lactoferrin: Structure, function and applications. Int J Antimicrob Agents 33: 301.e1-e8, 2009.

24. Moreno-Expósito L, Illescas-Montes R, Melguizo-Rodríguez L, Ruiz C, Ramos-Torrecillas $J$ and de Luna-Bertos E: Multifunctional capacity and therapeutic potential of lactoferrin. Life Sci 195: 61-64, 2018.

25. Hao L, Shan Q, Wei J, Ma F and Sun P: Lactoferrin: Major physiological functions and applications. Curr Protein Pept Sci 20: 139-144, 2019.

26. Elass-Rochard E, Legrand D, Salmon V, Roseanu A, Trif M, Tobias PS, Mazurier J and Spik G: Lactoferrin inhibits the endotoxin interaction with CD14 by competition with the lipopolysaccharide-binding protein. Infect Immun 66: 486-491, 1998.

27. Lu L, Hangoc G, Oliff A, Chen LT, Shen RN and Broxmeyer HE: Protective influence of lactoferrin on mice infected with the polycythemia-inducing strain of friend virus complex. Cancer Res 47: 4184-4188, 1987.

28. Oda H, Wakabayashi H, Tanaka M, Yamauchi K, Sugita C, Yoshida H, Abe F, Sonoda T and Kurokawa M: Effects of lactoferrin on infectious diseases in Japanese summer: A randomized, double-blinded, placebo-controlled trial. J Microbiol Immunol Infect, Feb 26, 2020 (Online ahead of print). 
29. Sano H, Nagai K, Tsutsumi $\mathrm{H}$ and Kuroki Y: Lactoferrin and surfactant protein A exhibit distinct binding specificity to $F$ protein and differently modulate respiratory syncytial virus infection. Eur J Immunol 33: 2894-2902, 2003.

30. Pietrantoni A, Di Biase AM, Tinari A, Marchetti M, Valenti P, Seganti L and Superti F: Bovine lactoferrin inhibits adenovirus infection by interacting with viral structural polypeptides. Antimicrob Agents Chemother 47: 2688-2691, 2003.

31. Lang J, Yang N, Deng J, Liu K, Yang P, Zhang G and Jiang C: Inhibition of SARS pseudovirus cell entry by lactoferrin binding to heparan sulfate proteoglycans. PLoS One 6: e23710, 2011.

32. Chen JM, Fan YC, Lin JW, Chen YY, Hsu WL and Chiou SS Bovine lactoferrin inhibits dengue virus infectivity by interacting with heparan sulfate, low-density lipoprotein receptor, and DC-SIGN. Int J Mol Sci 18: 1957, 2017.

33. Weng TY, Chen LC, Shyu HW, Chen SH, Wang JR, Yu CK, Lei HY and Yeh TM: Lactoferrin inhibits enterovirus 71 infection by binding to VP1 protein and host cells. Antiviral Res 67: 31-37, 2005.

34. Pietrantoni A, Fortuna C, Remoli ME, Ciufolini ME and Superti F: Bovine lactoferrin inhibits Toscana virus infection by binding to heparan sulphate. Viruses 7: 480-495, 2015.

35. Beljaars L, van der Strate BW, Bakker HI, Reker-Smit C, van Loenen-Weemaes AM, Wiegmans FC, Harmsen MC, Molema G and Meijer DK: Inhibition of cytomegalovirus infection by lactoferrin in vitro and in vivo. Antiviral Res 63: 197-208, 2004.

36. Ammendolia MG, Marchetti M and Superti F: Bovine lactoferrin prevents the entry and intercellular spread of herpes simplex virus type 1 in green Monkey kidney cells. Antiviral Res 76: 252-262, 2007

37. Ishikawa H, Awano N, Fukui T, Sasaki H and Kyuwa S: The protective effects of lactoferrin against murine norovirus infection through inhibition of both viral attachment and replication. Biochem Biophys Res Commun 434: 791-796, 2013.

38. Vellingiri B, Jayaramayya K, Iyer M, Narayanasamy A, Govindasamy V, Giridharan B, Ganesan S, Venugopal A, Venkatesan D, Ganesan H, et al: COVID-19: A promising cure for the global panic. Sci Total Environ 725: 138277, 2020.

39. Lan J, Ge J, Yu J, Shan S, Zhou H, Fan S, Zhang Q, Shi X, Wang Q, Zhang L and Wang X: Structure of the SARS-CoV-2 spike receptor-binding domain bound to the ACE2 receptor. Nature 581: 215-220, 2020.

40. van der Strate BW, Beljaars L, Molema G, Harmsen MC and Meijer DK: Antiviral activities of lactoferrin. Antiviral Res 52: 225-239, 2001.

41. Baker EN and Baker HM: Molecular structure, binding properties and dynamics of lactoferrin. Cell Mol Life Sci 62: 2531-2539, 2005

42. Kamhi E, Joo EJ,Dordick JS and Linhardt RJ: Glycosaminoglycans in infectious disease. Biol Rev Camb Philos Soc 88: 928-943, 2013.

43. Cagno V, Tseligka ED, Jones ST and Tapparel C: Heparan sulfate proteoglycans and viral attachment: True receptors or adaptation bias? Viruses 11: 596, 2019.

44. Bernard KA, Klimstra WB and Johnston RE: Mutations in the E2 glycoprotein of Venezuelan equine encephalitis virus confer heparan sulfate interaction, low morbidity, and rapid clearance from blood of mice. Virology 276: 93-103, 2000

45. Goodfellow IG, Sioofy AB, Powell RM and Evans DJ Echoviruses bind heparan sulfate at the cell surface. J Virol 75 : 4918-4921, 2001

46. Li P, Sheng J, Liu Y, Li J, Liu J and Wang F: Heparosan-derived heparan sulfate/heparin-like compounds: One kind of potential therapeutic agents. Med Res Rev 33: 665-692, 2013.

47. Zheng J: SARS-CoV-2: An emerging coronavirus that causes a global threat. Int J Biol Sci 16: 1678-1685, 2020.

48. Bartlam M, Yang H and Rao Z: Structural insights into SARS coronavirus proteins. Curr Opin Struct Biol 15: 664-672, 2005.

49. Belting M: Heparan sulfate proteoglycan as a plasma membrane carrier. Trends Biochem Sci 28: 145-151, 2003.

50. Carvalho CAM, Sousa IP Jr, Silva JL, Oliveira AC, Gonçalves RB and Gomes AMO: Inhibition of Mayaro virus infection by bovine lactoferrin. Virology 452-453: 297-302, 2014.
51. Jenssen $H$ and Hancock RE: Antimicrobial properties of lactoferrin. Biochimie 91: 19-29, 2009.

52. Yan R, Zhang Y, Li Y, Xia L, Guo Y and Zhou Q: Structural basis for the recognition of SARS-CoV-2 by full-length human ACE2. Science 367: 1444-1448, 2020

53. Gao C, Zeng J, Jia N, Stavenhagen K, Matsumoto Y, Zhang H, Li J, Hume AJ, Mühlberger E, van Die I, et al: SARS-CoV-2 spike protein interacts with multiple innate immune receptors. bioRxiv: 2020.07.29.227462, 2020

54. Brufsky A and Lotze MT: DC/L-SIGNs of hope in the COVID-19 pandemic. J Med Virol, May 6, 2020 (Online ahead of print).

55. Han DP, Lohani M and Cho MW: Specific asparagine-linked glycosylation sites are critical for DC-SIGN- and L-SIGN-mediated severe acute respiratory syndrome coronavirus entry. J Virol 81: 12029-12039, 2007.

56. Ahlawat $S$, Asha and Sharma KK: Immunological co-ordination between gut and lungs in SARS-CoV-2 infection. Virus Res 286: 198103, 2020

57. Dai YJ, Hu F, Li H, Huang HY, Wang DW and Liang Y: A profiling analysis on the receptor ACE2 expression reveals the potential risk of different type of cancers vulnerable to SARS-CoV-2 infection. Ann Transl Med 8: 481, 2020.

58. Puddu P, Carollo MG, Belardelli F, Valenti P and Gessani S: Role of endogenous interferon and LPS in the immunomodulatory effects of bovine lactoferrin in murine peritoneal macrophages. J Leukoc Biol 82: 347-353, 2007.

59. Puddu P, Valenti $P$ and Gessani S: Immunomodulatory effects of lactoferrin on antigen presenting cells. Biochimie 91: 11-18, 2009.

60. Siqueiros-Cendón T, Arévalo-Gallegos S, Iglesias-Figueroa BF, García-Montoya IA, Salazar-Martínez J and Rascón-Cruz Q: Immunomodulatory effects of lactoferrin. Acta Pharmacol Sin 35: 557-566, 2014.

61. Actor JK, Hwang SA and Kruzel ML: Lactoferrin as a natural immune modulator. Curr Pharm Des 15: 1956-1973, 2009.

62. Liu KY, Comstock SS, Shunk JM, Monaco MH and Donovan SM Natural killer cell populations and cytotoxic activity in pigs fed mother's milk, formula, or formula supplemented with bovine lactoferrin. Pediatr Res 74: 402-407, 2013.

63. MacManus CF, Collins CB, Nguyen TT, Alfano RW, Jedlicka P and de Zoeten EF: VEN-120, a recombinant human lactoferrin, promotes a regulatory $\mathrm{T}$ cell [Treg] phenotype and drives resolution of inflammation in distinct murine models of inflammatory bowel disease. J Crohns Colitis 11: 1101-1112, 2017.

64. Kuhara T, Yamauchi K, Tamura Y and Okamura H: Oral administration of lactoferrin increases NK cell activity in mice via increased production of IL-18 and type I IFN in the small intestine. J Interferon Cytokine Res 26: 489-499, 2006.

65. Haller O, Kochs G and Weber F: The interferon response circuit: Induction and suppression by pathogenic viruses. Virology 344 : $119-130,2006$

66. Legrand D: Overview of lactoferrin as a natural immune modulator. J Pediatr 173 (Suppl): S10-S15, 2016.

67. Wakabayashi H, Oda H, Yamauchi K and Abe F: Lactoferrin for prevention of common viral infections. J Infect Chemother 20: 666-671, 2014

68. Borchers AT, Chang C, Gershwin ME and Gershwin LJ: Respiratory syncytial virus-a comprehensive review. Clin Rev Allergy Immunol 45: 331-379, 2013.

69. Berlutti F, Pantanella F, Natalizi T, Frioni A, Paesano R, Polimeni A and Valenti P: Antiviral properties of lactoferrin-a natural immunity molecule. Molecules 16: 6992-7018, 2011.

70. Legrand D, Elass E, Carpentier M and Mazurier J: Lactoferrin: A modulator of immune and inflammatory responses. Cell Mol Life Sci 62: 2549-2559, 2005

This work is licensed under a Creative Commons Attribution-NonCommercial-NoDerivatives 4.0 International (CC BY-NC-ND 4.0) License. 